\title{
A Review on Reconfigurable Antennas for 4G and 5G Wireless Communications
}

\author{
Arpit Jain, Pallav Rawal \\ Department of Electronics and Communication Engineering, Swami Keshvanand Institute of Technology, \\ Management \& Gramothan, Jaipur, Rajasthan (INDIA) \\ E-mail: arpitjain3105@gmail.com \\ Received 01.02.2021, Received in revised form 19.03.2021, Accepted 25.03.2021
}

\begin{abstract}
Communication technologies steer by evolution shift need wireless organization to maneuver in reference to multi-function and high potency. Therefore, analysis development on reconfigurable antenna for swap electrical parameters in synchronous as per demand in suits operating state of antenna at any given time. Characteristics and basic properties with single and multiple reconfigurability modes area units investigated. Reconfigurable antennas square measure plan supported parameters like frequency, polarization and radiation. If associate antenna be reconfigurable into many nations need range of active parts. The long-established multi-antennas square measure replaced by a 1 and distinctive antenna. During this paper describe a frequency and polarization plan antenna understand by switch calibration with frequency switches, PIN diode or MEMS frequency switches and structure, that's mainly applicable in multi and single band spring matrix internet and understand amusing operate in between left and right orientated circular polarization in communication system.
\end{abstract}

Keywords-4G; 5G; Reconfigurable Antenna; Switch; PIN diode; MEMS; Wireless Communications

\section{INTRODUCTION}

Assembling defined as rearranging elements of 1 thing to understand a replacement thing, if required operational parameters of the antenna modification, then the antenna should be reconfigured or restored to satisfy the new specifications. Reconfigurable associate antennas modification their performance characteristics by neutering this flow on an antenna, victimization automatically elements shifters, attenuators, diodes, tunable materials, or active materials.

It modifies the antenna's emission, propagation, or bandwidth in some fascinating fashion. So, 2 or more antennas reinstate into 1 , to understand multiple ways. A reconfigurable antenna has parts which modify emission, propagation, or bandwidth. The concept of reconfiguring is relatively previous. In early, the two-element nulls employing tag section so as to see the direction of a sign [1]. Bruce and Beck modified dimensions of parallelogram antenna in Figure 1 by widen wires with external means [2]. Reconfiguring the consisted the space axis. [3]. The idea formed by azimuth antennas [4].
The antenna was fictitious throughout. It's an oversized circular part [5].

Earlier, "reconfigurability" outlined "the nature of change in shape of outward wave" [6]. dynamic modification had space satellite. [7]. reconfigurableantenna had large technologies applied with several examples [8].

This paper is related to technology. It started from oldest to the more-recent technologies. Thorough clarification with info and methodology and interesting technologies.

\section{AUTOMATICALLY MOVABLE ELEMENTS}

The first reconfigurable antennas had automatically movable components. Later Huge antennas feed to vary bandwidth, an exquisite later one is that the Arecibo spherical-reflector antenna [9]. It's conjointly potential to position nulls within the antenna signals stepping into the range $[10,11]$. Contortion mesh-reflector's surface mistreatment static $[7,12]$.

\section{RECONFIGURE ARRAYS}

An antenna array (or array antenna) may be a set of connected antennas together as one antenna, to transmit and received radio waves. Multiple antennas which are fed from an equivalent transmitter or receiver are an array antenna, or antenna array.

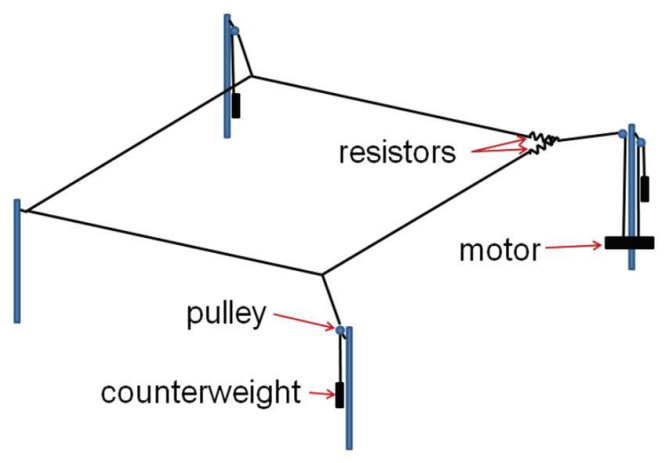

Fig.1 Uniform antenna 


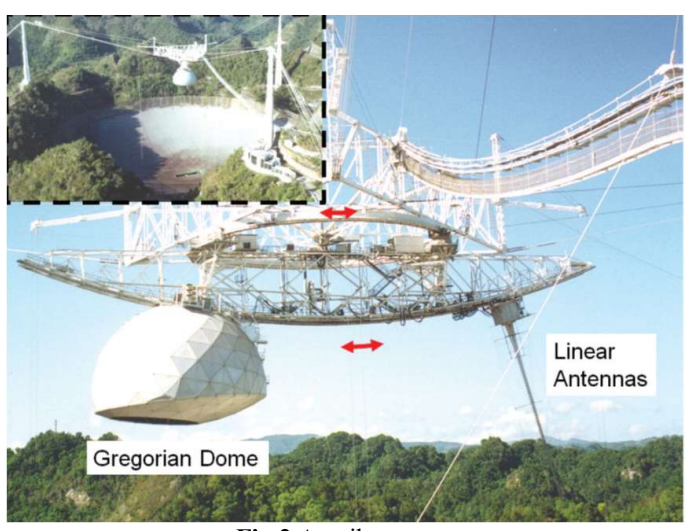

Fig.2 Arecibo antenna

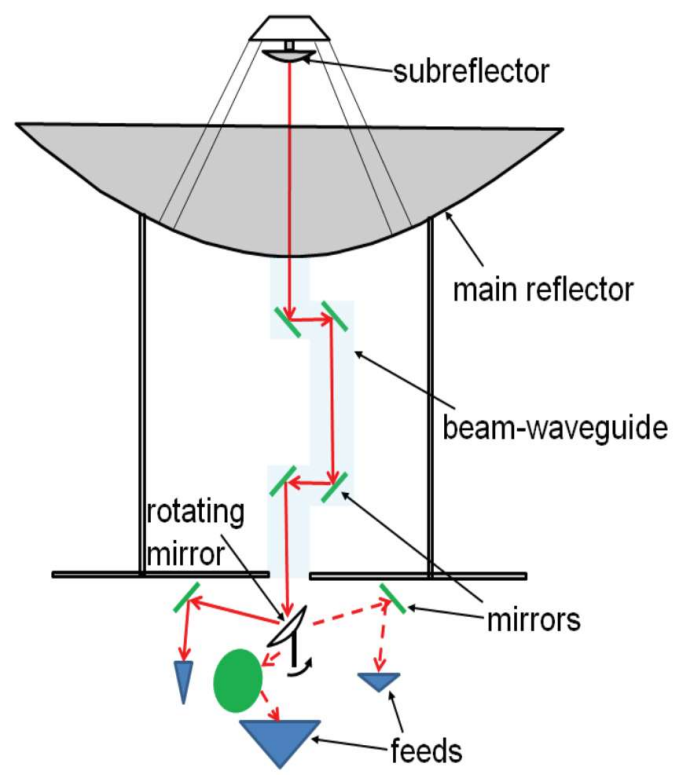

Fig.3 Beam-waveguide antenna

For instance, the TechSat 21 project investigated antenna parts on tiny satellite and aggregation for aperture. [18].

\section{RF SWITCHES}

After RF switch is passage high frequency signals. A Frequency (RF) switch may be a device that routes high-frequency signals through transmission paths. They also support the mixing of multiple radios that use one antenna.

Some vital characteristics of a switch area unit [19]. RF switch circuits are emerging as a practical solution to affect the switching speed, spacing, flexibility front-end, and filtering issues designers face within the sector of advanced wireless systems. The cut-off frequency [20] $f_{c}=\frac{1}{2 \pi C_{o f f} R_{o n}}$

Switches are wanted to reconfigure as substrate patches in 2D [22]. The verge of adjoin marks square measure bind with RF switches, so on customize adesirable patch antenna. Figure five slots modify during polarizations [23].



Fig.4 Reconfigurable microstrip patches

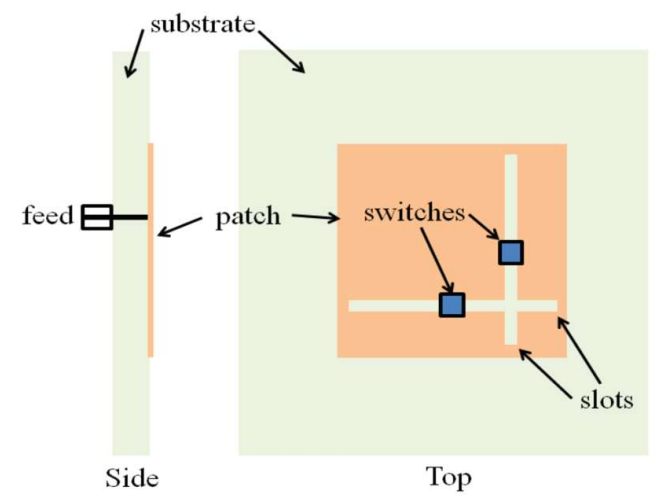

Fig.5 A reconfigurable slotted-patch antenna

\section{SEMICONDUCTOR SWITCH}

Figure 6 Semiconductors materials like silicon (Si), germanium $(\mathrm{Ge})$ and gallium arsenide $(\mathrm{GaAs})$, have electrical properties somewhere within the middle, between those of a "conductor" and an "insulator". They're not good conductors nor good insulators (hence their name "semi"-conductors). They need only a few "free electrons" because their atoms are closely grouped together in a crystalline pattern called a "crystal lattice" but electrons are still ready to flow, but only under special conditions. In [24] instructed victimization transistor switches in an exceedingly configuration a bit like Figure four. Another wide used is PIN diode [25]. In [23] prompt mistreatment of PIN-diode switches.

Variation between 2 forms switches is [26, 27]. Recently, a reconfigurable patch antenna by a biased diode [28].

- PIN diodes area unit current controlled, whereas FETs square area unit voltage controlled.

- PIN diodes have the pliability to manage giant RF signal power using lower control power.

- It susceptible to electrostatic-discharge (ESD) harm.

\section{MEMS SWITCHES}

MEMS switches created on silicon, quartz, glass made from mechanical. Figure eight shows 3 sorts 
of MEMS switches positions. In Figures 8a and 8b, shows working.

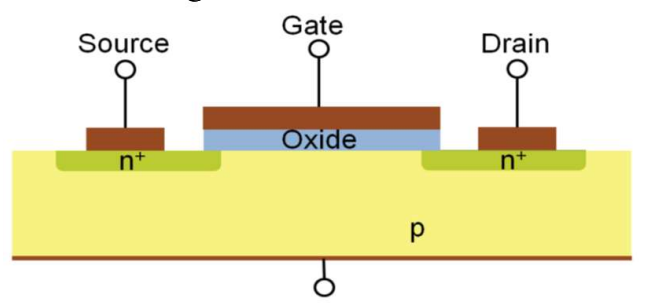

Fig.6 FET

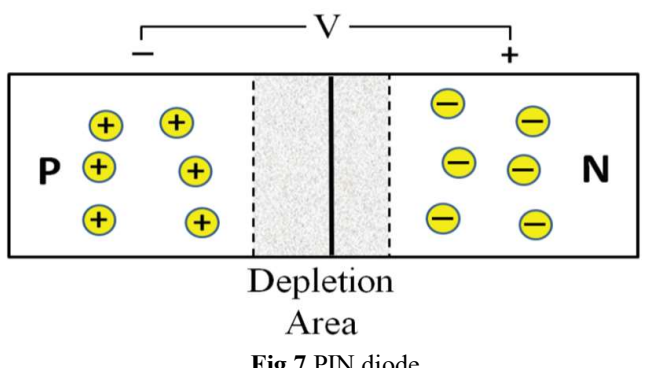

Fig.7 PIN diode



(a) Cantilever off

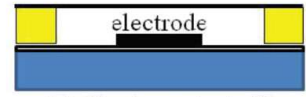

(c) Ohmic contact off.

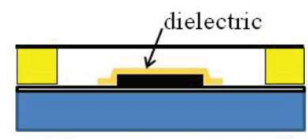

(e) Capacitive contact off

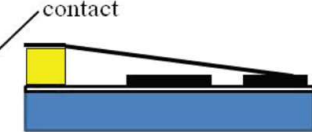

(b) Cantilever on.

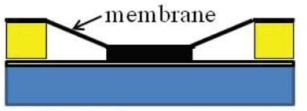

(d) Ohmic contact on

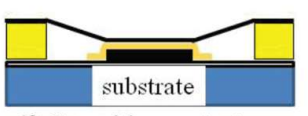

(f) Capacitive contact on
Fig.8 MEMS switches

Freshly, MEMS switches with near-stoichiometric films are flourishing [30].

RF-MEMS switches offer excellent reliability with superior precision and RF performance from $0 \mathrm{~Hz}$ (DC) to $14 \mathrm{GHz}$. They require only a low-voltage, low-current power supply and have a totally independent parallel logic control interface. They're offered in standard surface-mount space saving LFCSP plastic packages have low power consumption, low insertion loss, and high isolation, lightweight, like semiconductor switches [31].

MEMS switches projected to be utilized in late Nineties [29-32]. MEMS switch power for modification [33]. MEMS's are fancied employing various techniques, viable substrates devices [34].

\section{VARACTORS}

A varactors diode features terribly skinny layer like insulator (Figure 7) the quantitative capacitance with reverse bias.
It helpful for calibration the antenna. Varactors at diverging extend its terribly slim system of measurement to a system of measurement of regarding half-hour [35] Putting varactors with manageable 1st and 2nd resonant frequencies [36]. A partially-reflecting-surface (PRS) engineered [3739]. Pattern management has conjointly been incontestable victimization varactors.

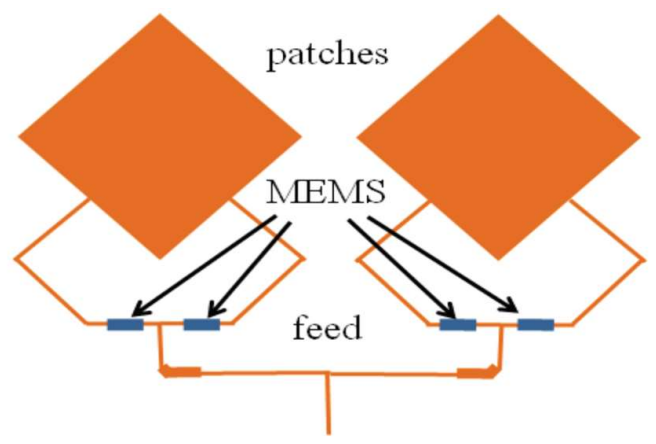

Fig.9 MEMS reconfigurable antenna

\section{CONCLUSIONS}

These antennas are here since a few years. Initially, they were supported physically. Arrays, Semiconductor and MEMS switches are famous in late Nineties. New approaches to antennas reconfigurablity materials requirement based upon present.

\section{REFERENCES}

[1] H. T. Friis, C. B. Feldman, and W. M. Sharpless, "The Determination of the Direction of Arrival of Short Radio Waves," Proceedings of the Institute of Radio Engineers, January (1934), Volume22, Issue 1 Pages 47-78.

[2] E. Bruce and A. C. Beck, "Experiments with Directivity Steering for Fading Reduction," Pro ceedings of the Institute of Radio Engineers, April (1935) Volume 23, Issue 4, Pages 357-371.

[3] H. T. Friis, and C. B. Feldman, "Multiple Unit Steerable Antenna for Short-Wave Reception," Proceedings of the Institute of Radio Engineers, July (1937) Volume 25 Issue 7, Pages 841-917.

[4] H. T. Friis and W. D. Lewis, "Radar Antennas," The Bell System Technical Journal, XXVI, 2, April (1947), XXVI, 2, Pages 219-317.

[5] R. L Haupt, Antenna Arrays: A Computational Approach, New York, Wiley, 2010.

[6] E. W. Matthews, C. L. Cuccia, and M. D. Rubin, "Technology Considerations for the Use of Mu ltiple Beam Antenna Systems in Communications Satellites," IEEE Transactions on Microwave Theory and Techniques,December (1979), Volume 27 Pages 998-1004.

[7] A. D. Monk and P. J. B. Clarricoats, "Adaptive Null Formation with a Reconfi gurable Refl ector Antenna," Proceedings of the Institute of Electrical Engineers Microwave Antennas and Propagation, June (1995) 142, 3 , June 1995, Pages 220-224.

[8] J. T. Bernhard, Reconfi gurable Antennas, San Rafael, CA, Morg an \& Claypool Publishers, (2007).

[9] D. A. Bathker, W. Veruttipong, T. Y. Otoshi, and P. W. Cramer, Jr., "Beam-Waveguide Antenna Performance Predic tions with Comparisons to Experimental Results," IEEE Transactions on Microwave Theor y and Techniques, 
June( 1992), 40, 6, Pages 1274-1285.

[10] D. Jacavanco, Refl ector Antenna Having Si delobe Suppression Elements, US Patent 4,631,547, December (1986) 23.

[11] R. L. Haupt, "Adaptive Nulling with a Refl ector Antenna Using Movable Scattering Elements," IEEE Transactions on Antennas and Propagation, 53, 2, February 2005, pp. 887-890.

[12] A. D. Monk and P. J. B. Clarricoats, "Adaptive Null Formation with a Reconfi gurable Refl ector Antenna," Proceed ings of the Institute of Electrical Engineers Microwave Anten nas and Propagation, June (1995) 142, 3, Pages 220-224.

[13] B. Tomasic, J. Turtle, L. Shiang et al., "The Geodesic Dome Phased Array Antenna for Satellite Control and Communication - Subarray Design, Development and Demonstration," IEEE International Symposium on Phased Array Sys tems and Technology, (2003), Pages 411-416.

[14] P. Rocca and R. L. Haupt, "Dynamic Array Thinning for Adaptive Interference Cancellation," Fourth European Conference on Antennas and Propagation (EuCAP), (2010), Pages 1-3.

[15] W. Kummer, A. Villeneuve, T. Fong, and F. Terrio, "UltraLow Sidelobes from Time-Modulated Arrays," IEEE Transactio ns on Antennas and Propagation, November (1963),Volume 11 Issue 6, Pages. 633-639

[16] "About ALMA Technology," http:// www.alma observatory. org/, May 27, (2009).

[17] National Radio Astrono my Observatory, "An Overview of the Very Large Array," http://www.vla. nrao.edu/genpub/ overview/, June 17, (2009).

[18] H. Steyskal, J. K. Schindler, P. Franchi et al., "Pattern Synthesis for Te chSat21 - A Distributed Space-Based Radar System," IEEE Antennas and Propagati on Magazine, August (2003) Volume 45, Issue 4, Pages 19-25.

[19] "Chapter 1: Understanding Key RF Switch Specifi ca tions," in National Instruments, The Guid e to Selecting an RF Switch, http://zone.ni.com/devzone/cda/tut/p/ id/5776.

[20] C. L. Goldsmith, Z. Yao, S. Eshelman, and D. Denniston, "Performance of Low-Loss RF MEMS Capacitive Switches," IEEE Mic rowave and Guided Wave Letters, August (1998), Volume 8 Issue 8 Pages 269-271

[21] "Solid State Switches," in the Microwave Encyclopedia, http://www.microwaves101.com/ encyclopedia/switches solidstate.cfm, November (2010), 18 .

[22] J. S. Herd, M. Davidovitz, and H. Steyskal, Reconfi gur able Microstrip Antenna Array Geometry which Utilizes Micro-Electro-Mechanical System (MEMS) Switches, US Patent 6, March 6, (2001), 198,438.

[23] F. Yang and Y. Rahmat-Samii, "A Reconfi gurable Patch Antenna Using Switchable Slots for Circu lar Polarization Diversity," IEEE Microwave and Wireless Components Letters, March (2002), Volume12, Issue 3, March (2002), Pages 96-98.

[24] L. N. Pringle, et al., "A Reconfi gurable Aperture Antenna Based on Switched Links Betwe en Electrically Small Metallic Patches," IEEE Transactions on Antennas and Propagation, June (2004), AP-52, 6 Pages 1434- 1445.

[25] The PIN Diode Circuit Designers' Handbook, Microsemi Corp., Watertown, MA, (1998).
[26] D. Gotch, "A Review of Technological Advances in SolidState Switches," Microwave Journal, November (2007), Volume 50 Issue 11, Pages 24-34.

[27] R. H. Caverly and G. Hiller, "Distortion Properties of MESFET and PIN Diode M icrowave Switches," IEEE Microwave Symposium, June(1992)， Volume 2 Pages 533-536.

[28] J. Choi a nd S. Lim, "Frequency Reconfi gurable Metamaterial Resonant Antenna," 2009 Asia Pacifi c Microwave Conference, APMC( 2009), Pages 798-801.

[29] E. R. Brown, "RF-MEMS Switches for Reconfi gurable Integrated Circuits," IEEE Transactions on Microwave Theory and Techniques, November(1998) Volume 46 Issue 11, Pages 1868-1880.

[30] S. J. Gross, S. Tadigadapa, T. N. Jackson, S. TrolierMcKinstry, and Q. Q. Zhang, "Lead-Zirconate-TitanateBased Piezoelectric Micromachined Switch," Applied Physics Letters, (2009). 83 ,Pages 174-176.

[31] P. D. Grant, M. W. Denhoff, and R. R. Mansour, "A Comparison Between RF MEMS and Semiconduc tor Switches," ICMENS, August 25-27, (2004), Pages 515521.

[32] S. Nikolaou, N. D. Kingsley, G. E. Ponchak, J. Papapolymerou, and M. M. Tentzeris, "UWB Elliptical Monopoles with a Reconfi gurable Band Notch Using MEMS Switches Actuated Without Bias Lines,” IEEE Transactions on Antennas and Propagation, AP-57, 8, August (2009), Pages 2242-2251.

[33] G. Wang, T. Po lley, A. Hunt, and J. Papapolymerou, "A High Performance Tunable RF MEMS Switch Using Barium Strontium Titanate (BST) Dielectrics for Reconfi gurable Antennas and Phased Arrays," IEEE Antennas and Wireless Propagation Letters, 4, (2005), Pages 217-220.

[34] G. Wang, D. Thompson, E. M. T entzeris, and J. Papapolymerou, "Low Cost RF MEMS Switches Using LCP Substrate," 34th European Microwave Conference, (2004), Pages 1441-1444.

[35] P. Bhartia and BAHL, "Frequency Agile Microstrip Antennas," Microwave Journal, October (1982), Volume 25 Issue 10, Pages 67-70.

[36] N. Behd ad and K. Sarabandi, "A Varactor-Tuned DualBand Slot Antenna," IEEE Transactions on Antennas and Propagation, AP-54, 2, February( 2006), Pages 401- 408.

[37] A. R. Weily, T. S . Bird, and Y. J. Guo, "A Reconfi gurable High-Gain Partially Refl ecting Surface Antenna," IEEE Transactions on Antenn as and Propagation, November (2008, AP-56, 11, Pages 3382-3390.

[38] H. Mirzaei and G. Eleftheriades, "A Compact FrequencyReconfi gurable Metamaterial-Inspired Antenn a," IEEE Antennas and Wireless Propagation Letters,(2011), pp. 1154-1157.

[39] L. Zhang, F. Yang, and A. Elsherbeni, "Analysis and Design of a Reconfi gurable Dual-Strip Scanning Antenna," IEEE Internat. 